\title{
BENS DE REDUZIDO VALOR
}

\author{
Paulo Filipe Aguiar \\ Manuel António Duarte
}

\section{RESUMO}

Pretende-se, com este pequeno texto, esclarecer de uma forma o mais abrangente possivel a dúvida existente sobre o que se considera um bem/elemento, de carácter duradouro ou não, de reduzido valor: A problemática tem implicações na forma de relevar tais bens/elementos, pois questiona-se a aplicabilidade do principio contabilístico geralmente aceite (pcga) da materialidade, em detrimento da explicasăo estabelecida na Classe 4 do Plano Oficial de Contabilidade (POC).

\section{Introdução}

Para um melhor entendimento da expressâo «reduzido valor» começaremos por firmar alguns conceitos:

- Bens/Elementos de consumo (curto prazo): o art. 208. . do Código Civil define-os como «[c]oisas cujo o us• regular importa a sua destruição ou a sua alienação»;

- Bens/Elementos duradouros (médio e longo prazo'): no POC²,

\footnotetext{
' Crédito a curto prazo, médio e longo prazo. Em Portugal, a definição de crédito a curto, médio e longo prazos está regulamentada pelo Decreto-Lei n. ${ }^{\circ} 344 / 78$, de 17/11. De acordo com este diploma, considera-se: Crédito a curto prazo, quando o prazo de vencimento não exceder um ano; crédito de médio prazo, quando o vencimento for superior a um ano, mas não a cinco anos; crédito a longo prazo, quando o prazo de vencimento exceder cinco anos.

${ }^{2}$ Aprovado pelo Dec.-Lei n. ${ }^{\circ} 410 / 89$, de 21 de Novembro.
} 
nas suas notas explicativas à Classe 4 , $1 \hat{\mathrm{e}}-\mathrm{se}$ : «[e]sta classe inclui os bens detidos com continuidade ou permanência e que não se destinem a ser vendidos ou transformados no decurso normal das operaçóes da empresa, quer sejam de sua propriedade, quer estejam em regime de locação tinanceira».

Ao pressupor-se a permanência, implicitamente está a definir-se médio e longo prazo: Poderá concluir-se que um bem/elemento de carácter duradouro é aquele que não será destruído ou alienado a curto prazo.

- O princípio contabilístico geralmente accite da materialidade diznos que: «a|s demonstrações financeitas devem evidenciar todos os elementos que sejam relevantes e que possam afectar avaliaçŏes ou decisôes pelos utentes interessados»?!

- Flementos de reduzido valor: «[r]clativamente a elementos do activo imobilizado sujeitos a deperecimento cujos valores unitários não ultrapassem $40000 \$$ ( $($ 199,52), ć accite a dedução num só excrécio do respectivo custo de aquisição ou de produção, excepto quando façam parte integrante de um conjunto de elementos que deva ser reintegrado ou amortizado como um todos"

Todos os bens/elementos do activo lixo (Af) são reintegráveis, sendo a reintegraçào calculada segundo métodos bem definidos, mas os bens/elementos de reduzido valor reintegram-se num só exercício.

\section{Divergências}

Face alo exposto, eabe referir que a interpretação literal do princípio contabilistico geralmente aceite da materialidade levaria a que todos os bens/elementos com reduzido valor (materialidade" baixa) não fossem sequer relevados, pois a sua relevância nas Demonstaçõos

\footnotetext{
Não se questiona neste lexto a problenática da alienação de um bem/elemento do imobilizado corpóreo no próprio exercicio en qué é adquirido.

"Capítulo 4 do Dec. Lei $11 . " 410 / 89$, de 21 de Novembro (POC).

"Cl. art 32." do Código do Imposto sobte o Rendimento das Pessoas Colectivas (CIRC) - Glementos de redurido valor.

"Sogundo o Dicionatio de lingua Portuguesa: «Qualidade do que é material. Ou seja que dir respeito à matéría, [...] corpóteo, pesado, [...] aquilo de que um corpo é feitos.
} 
Financeiras não seria susceptivel de influenciar as decisòes dos utentes ${ }^{7}$ da informação.

Deste modo, pensamos existir uma designaçào pouco feliz para este princípio, que deveria ser, conforme o $\mathrm{POC}$ preconiza, uma característica qualitativa da informação financeira".

No segundo parágrafo do ponto 3.2.1 do POC pode ler-se: «[a]ssim, al informação é de relevância matcrial se a sua omissão ou erro forem susecptiveis de influenciar as decisóes dos leitores com base nessa informação linanceira». Nestes termos, o que se trata de saber é se a «omissão ou erro» da informação são capazes de influenciar a decisão nele baseada e não, propriamente se o bem/elemento é de reduzido ou escasso valor.

Note-se, por último, que as Demonstraçòes Financeiras devem apresentar uma imagem verdadeira e apropriada da posiçăo financeira e do resultado das operaçóes de empresa", ou seja, existindo documento, há-de este ser sempre relevado.

\section{Como relevar os bens de reduzido valor}

A introdução feita à materialidade serve para entrar no ponto de discórdia quanto à relevação contabilística de bens/elementos de reduzido valor, onde alguns profissionais e académicos propõem a relevação como custo do exercício e outros como activo fixo (imobilizado corpóreo). Assim, qual deve ser a relevação correcta de tais bens/elementos? Será um problema de materialidade ou não?

\section{Relevação}

Para sermos uniformes com as regras de relevação contabilisticas definidas na normalização nacional, em vigor nesta data, se um

\footnotetext{
'Users dos anglo-saxónicos.

"A relevância é entendida como a qualidade cue a informaçăo ten de influenciar as decisöes dos utentes, ao ajuda-los a avaliar os acontecimentos passados, presentes e futuros ou a conlimar ou corrigir as suas avaliaçoes: clis. Capílulo 3, ponto 3.2.1 do POC.

"Cfr. Capilulo 3, ponto 3.2, do POC.
} 
bem/elemento tem forma física e carácter duradouro" ${ }^{10}$, deverá ser relevado como um activo fixo (imobilizado corpóreo).

Tomando em consideração:

i. A conceituação da Classe 4;

ii. As notas explicativas do POC sobre a subconta 62215 Ferramentas e utensílios de desgaste rápido («respeita ao equipamento dessa natureza cuja vida útil não exceda, em condições de utilização normal, o período de um ano») $\mathrm{c}$

iii. O que define o CIRC no art. 32.",

facilmente se verifica que, de reduzido valor ou não, será sempre relevado como imobilizado corpóreo.

Salientamos a expressão transcrita «em condições de utilização normal»: um bem/clemento duradouro, embora de reduzido valor, deve ser considerado como um activo fixo (Af) e não como um custo do exercício, que simplesmente o define como consumido e não reutilizável ou, diríamos mesmo, vendável.

Para reforçar a ideia anterior, socorremo-nos de alguma normalização contabilística curopcia e internacional:

$« \mathrm{O}$ activo imobilizado compreende os elementos do património que se destinam a servir de maneira durável à actividade da cmpresa»".

«Um activo é um recurso controlado pela empresa como resultado de acontecimentos passados e do qual se espera que fluam para a empresa benefícios económicos futuros.

Um activo pode ser:

a) usado singularmente ou sem combinação com outros activos na produção de bens e serviços para serem vendidos pela empresa;

b) trocado por outros activos;

c) usado para liquidar um passivo;

d) distribuido aos detentores da empresay".

\footnotetext{
"Cfr. notas explicativas da Classe 4 e da subconta 62215 - Ferramentas e utensílios de desgaste rápido.

"Cfr. art. 15." da IV Directiva (78/660/CEE), de 25 de Julho de 1978.

"Cfr. a IAS - Estrutura Conceptual para a Preparação e Apresentação das Demonstrações Financeiras, do IASB.
} 


\section{O problema da materialidade}

Em resposta à utilização ou não do princípio contabilístico geralmente aceite da materialidade, e atendendo à normalização vigente em Portugal, não cstaremos perante situações de «erros ou omissões» que sejam relevantes para a informação financeira, mas tratar-se-á, sim, da classificação de Activos e de Custos. Há, no entanto, quem tente justificar a relevação contabilística dos bens de reduzido valor como um custo do exercício, baseando-se na teoria do custo-benefício com o tratamento das imobilizações ${ }^{13}$. A expressão «erros ou omissões» subentende a relevação contabilística ou não de determinado documento ou comprovante.

\section{Mapa de Reintegrações e Amortizações}

Segundo o Mapa de Reintegrações e Amortizações ${ }^{14} \mathrm{em}$ vigor, os bens de reduzido valor deverão ser evidenciados pelo seu valor global em linha própria com a designação «Elementos de reduzido valor» (cfi: notas explicativas apresentadas no verso deste Mapa).

\section{Exemplo sinóptico. Conclusões}

Como conclusão, e para que se perceba mais cabalmente a exposição precedente, damos como exemplo a relevação contabilística de um Telemóvel no valor de $€ 109,99$ (com IVA incluído à taxa de $19 \%$ ), pago em cheque, em 01.07.2003.

$$
\begin{aligned}
& \text { Custo de Aquisição }=€ 109,99 /(1+0,19)=€ 92,43 \\
& \text { IVA dedutível }=€ 92,43 * 0,19=€ 17,56 .
\end{aligned}
$$

Este mesmo telemóvel, após o encerramento do exercício de 2003, será entregue em retoma por troca de um novo telemóvel, em 01.04.2004, de valor $€ 440,00$ (IVA incluído à taxa de 19\%), sendo-lhe atribuído um valor de $€ 49,90$ (IVA incluído à taxa de 19\%). Este novo telemóvel será pago de imediato, através de cheque.

\footnotetext{
${ }^{13}$ Preenchimento dos Mapas de Reintegrações e Amortizações e criação da ficha das imobilizações.

${ }^{14}$ Cfi. art. 121. "do CIRC - Portaria n. ${ }^{\circ} 359 / 2000$, de 20/06. Modelo n." 1746 do INCM.
} 
Relevação:

(valores cme)

\begin{tabular}{|c|c|c|c|c|}
\hline \multirow[t]{2}{*}{ Operaçño } & \multicolumn{2}{|c|}{$\begin{array}{l}\text { Como Custo (atilizando o } \\
\text { principio da materialidade) }\end{array}$} & \multicolumn{2}{|c|}{$\begin{array}{l}\text { Como Activo Fixo (atilizando as } \\
\text { definiçoes dadas pelo POC) }\end{array}$} \\
\hline & Débito & Crédito & Débito & Crédito \\
\hline Aquisiço cm $01.07 .0 \mathrm{X}$ & $\begin{array}{l}62215-92,43 \\
24323-17,56\end{array}$ & $221 \quad 109,99$ & $\begin{array}{rr}426 & 92,43 \\
24322 & 17,56\end{array}$ & $2611-109,99$ \\
\hline P'agamento & $221 \quad 109,99$ & $121 \quad 109,99$ & $2611-109,99$ & $121 \cdot 109,99$ \\
\hline $\operatorname{lin1} 31.12 .200 \mathrm{X}$ & -16 & - & $6626 \ldots 92,43^{17}$ & $4826 \quad 92,43$ \\
\hline $\begin{array}{l}\text { Ayuisiçio de novo } \\
\text { celemóvel }\end{array}$ & $\begin{array}{cr}426 & 369,75 \\
24322 & \cdots \\
\end{array}$ & $2011 \cdots 440,00$ & $\begin{array}{cr}426 & 369,75 \\
24322 & 70,25 \\
\end{array}$ & $2611 \quad 440,00$ \\
\hline Retoma & $268 \quad 49,90$ & $\begin{array}{l}798^{(0)}-41.93 \\
24331 \quad 7.97\end{array}$ & $\begin{array}{ll}4826 & 92,43 \\
7942 & 92,43 \\
& \\
268 & 49,90\end{array}$ & $\begin{array}{rr}7942 & 92,43 \\
426 & 92,43 \\
& \\
7942 & 41,93 \\
24331 & 7,97\end{array}$ \\
\hline Palgiamento & 2611440,00 & $\begin{array}{lr}268 & 49,90 \\
121 & 390,10\end{array}$ & $2611 \quad 440,00$ & $\begin{array}{r}268 \\
121-39,90 \\
1210\end{array}$ \\
\hline
\end{tabular}

A terminar, uma breve referência às complicações que a relevação pela opção do custo traria. Ao nível da Declaração anual (anexo L) como se iria indicar a liquidação do IVA na operação citada: como venda de bens (não sendo essa a actividade da empresa) ou como venda de imobilizado (onde o bem não consta)? Conforme se verifica, também por esta opção o custo-benefício ${ }^{20}$ pode não ser a justificação do respectivo tratamento contabilístico.

1s Cfr. a função do bem/elemento, isto é, equipamento básico (423) para empresas com o ramo de actividade direccionado para as comunicações (exemplo: vendas por telefone) ou equipamento administrativo (426) para empresas com o ramo de actividade direccionado para o comércio (exemplo: compra e venda de viaturas).

16 Tendo sido considerado como custo, nada se faz, apenas se transforma cm dedução aos proveitos.

${ }^{17}$ Reintegrado em 100\%, ao abrigo do art. 32." do CIRC.

is Tendo em conta o valor do bem/elemento, terá sempre de ser considerado como activo fixo (Af) (€ 369,75).

${ }^{19}$ Ao não existir qualquer indicação do bem, todo o valor da retoma será um proveito. Neste contexto, poderá ser considerado como proveito operacional (76) ou extraordinário (79). Caso se use o extraordinário, poder-se-á sc utilizar a subconta 797 ou 798 (no exercício anterior havia sido considerado como um custo).

to Esta justificação serve para o exemplo adoptado. 